\title{
INTERNATIONAL JOURNAL OF INNOVATION - IJI COMPLETES 7 YEARS
}

\author{
Editorial comment
}

Isabel Cristina Scafuto

Scientific Editor

Priscila Rezende da Costa

Editor-in-Chefe

Marcos Rogerio Mazzieri

Scientific Editor

Cite as - American Psychological Association (APA)

Scafuto, I. C., Costa, P. R., \& Mazzieri, M. R. (2020, May/Aug.). International Journal of Innovation - IJI completes 7 years. Editorial comment. International Journal of Innovation - IJI, São Paulo, 8(2), 1-6. https://doi.org/10.5585/iji.v8i2.17965.

International Journal of Innovation - IJI has now 7 years old! In this editorial comment, we not only want to talk about our evolution but get even closer to the IJI community. It is our first editorial comment, a new IJI's communication channel. Some of the changes are already described on our website.

IJI is an innovation-focused journal that was created to support scientific research and thereby contribute to practice. Also, IJI was born internationally, receiving and supporting research from around the world. We welcome articles in Portuguese, English, and Spanish.

We have published eight volumes in IJI since 2013, totaling 131 articles. Our journal is indexed in: Dialnet and Red Iberoamericana de Innovación y Conocimiento Científico; Ebsco Host; Erih Plus; Gale - Cengage Learning; Latindex; Proquest; Redalyc; Web of Science Core Collection (Emerging Sources Citation Index), among others. We provide free access "open access" to all its content. Articles can be read, downloaded, copied, distributed, printed and / or searched.

We want to emphasize that none of this would be possible without the authors that recognized in IJI a relevant journal to publicize their work. Nor can we fail to mention the 
tireless and voluntary action of the reviewers, always contributing to the articles' improvement and skilling up our journal, more and more.

All editors who passed through IJI have a fundamental role in this trajectory. And, none of this would be possible without the editorial team of Uninove. Everyone who passed and the current team. We want to express that our work as current editors of IJI would not be possible without you.

\section{Changes in the Intenational Journal of Innovation - IJI}

As we mentioned earlier, IJI was born in 2013. And, over time, we are improving its structure always to improve it. In this section, we want to show some changes we made. We intend that editorial comments become a communication channel and that they can help our readers, authors, and reviewers to keep up with these changes.

Although IJI is a comprehensive Innovation journal, one of the changes we want to inform you is that now, at the time of submission, the author will choose one of the available topics that best suit your article. The themes are: Innovative Entrepreneurship; Innovation and Learning; Innovation and Sustainability; Internationalization of Innovation; Innovation Systems; Emerging Innovation Themes and; Digital Transformation. Below, we present each theme so that everyone can get to know them:

- Innovative Entrepreneurship: emerging markets provided dynamic advantages for small businesses and their entrepreneurs to exploit the supply flows of resources, capacities, and knowledge-based on strategies oriented to the management of innovation. Topics covered in this theme include, for example: resources and capabilities that support innovative entrepreneurship; innovation habitats (Universities, Science and Technology Parks, Incubators and Accelerators) and their influences on the development of knowledge-intensive spin-offs and start-ups; open innovation, triple/quadruple helix, knowledge transfer, effectuation, bricolage and co-creation of value in knowledge-intensive entrepreneurship ecosystems; and adequate public policies to support innovative entrepreneurship.

- Innovation and Learning: discussions on this topic focus on the relationship between learning and innovation as topics with the potential to improve teaching and learning. They also focus on ways in which we acquire knowledge through innovation and how knowledge encourages new forms of innovation. Topics covered in this theme include, for example: innovative projects for learning; innovation-oriented learning; absorptive capacity; innovation 
in organizational learning and knowledge creation; unlearning and learning for technological innovation; new learning models; dynamics of innovation and learning; skills and innovation.

- Innovation and Sustainability: discussions on this topic seek to promote the development of innovation with a focus on sustainability, encouraging new ways of thinking about sustainable development issues. Topics covered in this theme include, for example: development of new sustainable products; circular economy; reverse logistic; smart cities; technological changes for sustainable development; innovation and health in the scope of sustainability; sustainable innovation and policies; innovation and education in sustainability and social innovation.

- Internationalization of Innovation: the rise of developing countries as an innovation center and their new nomenclature for emerging markets have occupied an important place in the international research agenda on global innovation and Research and Development (R\&D) strategies. Topics covered in this theme include, for example: resources and capabilities that support the internationalization of innovation and R\&D; global and local innovation and $R \& D$ strategies; reverse innovation; internationalization of start-ups and digital companies; development of low-cost products, processes and services with a high-value offer internationalized to foreign markets; innovations at the base of the pyramid, disruptive and/or frugal developed and adopted in emerging markets and replicated in international markets; institutional factors that affect firms' innovation efforts in emerging markets.

- Innovation Systems: regulation and public policies define the institutional environment to drive innovation. Topics include industrial policy, technological trends and macroeconomic performance; investment ecosystem for the development and commercialization of new products, based on government and private investments; investment strategies related to new companies based on science or technology; Technology transfer to, from and between developing countries; technological innovation in all forms of business, political and economic systems. Topics such as triple helix, incubators, and other structures for cooperation, fostering and mobilizing innovation are expected in this section.

- Emerging Themes: from the applied themes, many emerging problems have a significant impact on management, such as industry 4.0, the internet of things, artificial intelligence or social innovations, or non-economic benefits. Intellectual property is treated as a cognitive database and can be understood as a technological library with the registration of the product of human creativity and invention. Social network analysis reveals the relationships between transforming agents and other elements; therefore, encouraged to be used in research 
and submitted in this section. The theoretical field not fully developed is not a barrier to explore any theme or question in this section.

- Digital Transformation: this interdisciplinary theme covers all the antecedents, intervening, and consequent effects of digital transformation in the field of technology-based companies and technology-based business ventures. The technological innovator (human side of innovation) as an entrepreneur, team member, manager, or employee is considered an object of study either as an agent of innovation or an element of the innovation process. Digital change or transformation is considered as a process that moves from the initial status to the new digital status, anchored in the theories of innovation, such as adoption, diffusion, push / pull of technology, innovation management, service innovation, disruptive innovation, innovation frugal innovation economy, organizational behavior, context of innovation, capabilities and transaction costs.

Authors who submit to IJI will realize that they now need to make a structured summary at the time of submission. The summary must include the following information:

- $($ maximum of 250 words + title + keywords $=$ Portuguese, English and Spanish $)$

- Title

- Objective of the study (mandatory): Indicate the objective of the work, that is, what you want to demonstrate or describe.

- Methodology / approach (mandatory): Indicate the scientific method used in carrying out the study. In the case of theoretical essays, it is recommended that the authors indicate the theoretical approach adopted.

- Originality / Relevance (mandatory): Indicate the theoretical gap in which the study is inserted, also presenting the academic relevance of the discipline.

- Main results (mandatory): briefly indicate the main results achieved.

- Theoretical-methodological contributions (mandatory): Indicate the main theoretical and / or methodological implications that have been achieved with the results of the study.

- Social / managerial contributions (mandatory): Indicate the main managerial and / or social implications obtained through the results of the study.

- Keywords: between three and five keywords that characterize the work 
Another change regarding the organization of the IJI concerns the types of work. In addition to the Editorial Comment and Articles, the journal will include Technological Articles, Perspectives, and Reviews. Thus, when submitting a study, authors will be able to choose from the available options for types of work. Throughout the next issues of the IJI, in the editorial comments, we will pass on pertinent information about every kind of work, to assist the authors in their submissions.

Currently, the IJI is available to readers with new works three times a year (JanuaryApril; May-August; September-December) with publications in English, Portuguese and Spanish. From what comes next, we will have some changes in the periodicity.

\section{Next steps}

As editors, we want the IJI to continue with a national and international impact and increase its relevance in the indexing bases. For this, we will work together with the entire editorial team, reviewers, and authors to improve the work. We will do our best to give full support to the evaluators who are so dedicated to making constructive evaluations to the authors. We will also support authors with all the necessary information.

With editorial comments, we intend to pass on knowledge to readers, authors, and reviewers to improve the articles gradually. We also aim to support classroom activities and content.

Even with the changes reported here, we continue to accept all types of work, as long as they have an appropriate methodology. We also maintain our scope and continue to publish all topics involving innovation. We want to support academic events on fast tracks increasingly.

\section{About the articles in this edition of IJI}

This issue is the first we consider the new organization of the International Journal of Innovation - IJI. We started with this editorial comment talking about the changes and improvements that we are making at IJI-as an example, showing the reader, reviewer, and author that the scope remains the same. However, at the time of submission, the author has to choose one of the proposed themes and have a mandatory abstract structured in three languages (English, Portuguese, and Spanish).

In this issue, we have a section of perspectives that addresses the "Fake Agile" phenomenon. This phenomenon is related to the difficulties that companies face throughout the 
agile transformation, causing companies not to reach full agility and not return to their previous management model.

Next, we publish the traditional section with scientific articles. The article "Critical success factors of the incubation network of enterprises of the IFES” brings critical success factors as the determining variables to keep business incubators competitive, improving their organizational processes, and ensuring their survival. Another published article, "The sharing economy dilemma: the response of incumbent firms to the rise of the sharing economy", addresses the sharing economy in terms of innovation. The results of the study suggest that the current response to the sharing economy so far is moderate and limited. The article "Analysis of the provision for implementation of reverse logistics in the supermarket retail" made it possible to observe that through the variables that define retail characteristics, it is not possible to say whether a supermarket will implement the reverse logistics process. And the article "Capability building in fuzzy front end management in a high technology services company", whose main objective was to assess the adherence among Fuzzy Front End (FFE) facilitators, was reported in the literature its application in the innovation process of a company, an innovative multinational high-tech services company.

We also published the article "The evolution of triple helix movement: an analysis of scientific communications through bibliometric technique". The study is a bibliometric review that brings essential contributions to the area. This issue also includes a literature review entitled "Service innovation tools: a literature review" that aimed to systematically review the frameworks proposed and applied by the literature on service innovation.

The technological article "A model to adopt Enterprise Resource Planning (ERP) and Business Intelligence (BI) among Saudi SMEs", in a new IJI publication section, addresses the main issues related to the intention to use ERPBI in the Saudi private sector.

As we mentioned earlier in this editorial, IJI has a slightly different organization. With the new format, we intend to contribute to the promotion of knowledge in innovation. Also, we aim to increasingly present researchers and students with possibilities of themes and gaps for their research and bring insights to professionals in the field.

Again, we thank the reviewers who dedicate their time and knowledge in the evaluations, always helping the authors. We wish you, readers, to enjoy the articles in this issue and feel encouraged to send your studies in innovation to the International Journal of Innovation - IJI. 